\title{
TRADISI NAMPAH BATU SEBAGAI UPAYA PEMBENTUKAN KARAKTER DAN PENGEMBANGAN MATA PELAJARAN IPS KELAS VII SMP N 5 KUBUTAMBAHAN
}

\author{
I Made Deta Barry Suhartawan \\ Program Studi Pendidikan IPS Universitas Pendidikan Ganesha, Singaraja \\ E-mail:deta_milanisti@yahoo.co.id'1 ,nengah.bawa@pasca.undiksha.ac.id², tuty.maryati@undiksha.ac.id ${ }^{3}$
}

\begin{abstract}
Abstrak
Tujuan dari penelitian ini adalah; 1) mengetahui alasan penggunaan batu sebagai sarana utama dalam tradisi nampah batu, 2) mengetahui prosedur tahapan dan proses ritual tradisi nampah batu di desa pakraman Depeha, 3) mengetahui nilai religius, nilai toleransi, nilai kerja sama, nilai disiplin, nilai tanggungjawab, nilai gotong royong yang terkandung dalam ritual tradisi nampah batu berdasarkan kurikulum 2013,4$)$ memahami pengintegrasian tradisi nampah batu di Desa Depeha ke dalam RPP di SMP Negeri 5 Kubutambahan. Metode yang digunakan dalam penelitian adalah metode penelitian kualitatif. Lokasi penelitian dilaksanakan di Desa Depeha, tepatnya di SMP N 5 Kubutambahan, data diperoleh melalui wawancara mendalam, observasi dan studi dokumen. Data penelitian selanjutnya diolah melalui tiga tahapan, yaitu: 1) reduksi data, 2) penyajian data, 3) analisis data dan penarikan kesimpulan. Hasil penelitian ini menunjukkan bahwa; 1) tradisi nampah batu merupakan simbol tanda penghormatan terhadap leluhur yang bermakna positif terkait kehidupan manusia, 2) Pelaksanaan tradisi nampah batu dilaksanakan pada purnama karo yang bertepatan pada bulan agustus, 3) Terdapat 6 nilai karakter yaitu nilai religius, nilai toleransi, nilai kerja sama, nilai disiplin, nilai tanggungjawab, nilai gotong royong yang tercermin dan terepresentasikan pada tradisi nampah batu, 4) Pengintegrasian nampah batu dapat dipresentasikan kedalam nilai-nilai karakter yang berpedoman pada pegangan hidup.
\end{abstract}

Kata kunci: Tradisi Nampah Batu, Nilai-nilai Karakter dari Tradisi Nampah, Pengayaan Sumber Pembelajaran IPS.

\begin{abstract}
The purpose of this research is; 1) Knowing the reasons for using Stone as the main means in the tradition of nampah batu. 2) To know the procedure of stages and ritual process of stone nampah tradition in Pakraman Depeha village.3 Knowing the values religious value, tolerance value, value of cooperation, value of discipline, responsibility value, togethernes values based on the curriculum 2013. 4) Understanding the integration of stone smug tradition in Depeha Village into RPP in SMP Negeri 5 Kubutambahan. The method used in this research is qualitative research method, the location of the research was conducted in Depeha Village, precisely in SMP N 5 Kubutambahan, data were obtained through in-depth interviews, observations and document studies. This data is further processed through three stages, namely: 1) data reduction, 2) data presentation, 3) data analysis and drawing conclusions. The results of this study indicate that; 1) nampah batu tradition is a symbol of honor to the ancestors with positive meaning related to human life, 2) The implementation of stone rub tradition is carried out at full moon karo coinciding in August, 3) There are 6 values of character that is religious value, tolerance value, value of cooperation, value of discipline, responsibility value, togethernes values reflected and represented on nampah batu rubble tradition, 4) 4) The integration of a rock can be presented into the values of the character guided by the handle of life.
\end{abstract}

Keywords: Nampah Batu Tradition, Character Values from Nampah Batu Tradition, Enrichment of IPS Learning Resources

\section{Pendahuluan}

Banyaknya tradisi kebudayaan dan kesenian yang dimiliki Bali memiliki makna dan fungsi tersendiri, sehingga kesenian dan tradisi yang dilaksanakan memiliki perbedaan dari pengeluaran biaya. Melihat serangkaian Tradisi dan kesenian Bali jika digunakan untuk hal keagamaan maka jumlah biaya yang dikeluarkan tidaklah sedikit. Pemeliharaan kebudayaan Bali sebagai sumber daya ekonomi hingga saat ini sepenuhnya menjadi tanggungan masyarakat desa. Biaya ini mencakup seluruh yang dikeluarkan oleh individu, keluarga, kelompok keluarga/klan, kelompok sekeha, dan kelompok masyarakat yang terhimpun 
dalam satu desa. Sekalipun belum pernah diteliti secara khusus, pengeluaran untuk pemeliharaan budaya itu sangatlah besar. Masyarakat Bali tidak pernah mengkalkulasi dan mengeluhkan besaran biaya itu. Basis filosofi penyelenggaraan pengembanan budaya tersebut adalah keiklasan dan rasa bhakti kepada Tuhan yang berurat dan berakar pada ajaran agama Hindu (Nurjaya, 2011).

Desa Depeha merupakan Desa Bali Aga yang merupakan penduduk asli Bali yang menggunakan tradisi asli seperti tradisi yang terkenal sampai saat ini yaitu tradisi nampah batu. Tradisi nampah batu adalah suatu adat atau kebiasaan "menyembelih batu" yang dilaksanakan oleh warga Desa Depeha yang diwariskan secara turun-temurun kepada generasi berikutnya yang merupakan rangakaian dari upacara Piodalan di Pura Puseh Desa Depeha. Pelaksanaan Upacara Nampah Batu mempunyai latar belakang etnografi yang berkaitan dengan cerita yang bersifat supernatural yang menceriterakan hubungan antara Dewi Danu yang berstana di Pura Ulun Danu Batur Kintamani dengan Ratu Ayu Manik Galih yang dipuja oleh masyarakat Desa Depeha sebagai Dewi Kesuburan, distanakan di Pura Puseh Desa Depeha. Hal yang menjadi daya tarik peneliti mengambil tradisi nampah batu adalah digunakannya batu sebagai sarana pengganti babi, dan setelah di potong batu tersebut diletakan di tengah pura puseh dan keesokan harinya hilang entah kemana. Hal yang kedua yaitu saat batu tersebut di potong, dagingnya diganti dengan hasil-hasil bumi yang ada di Desa Depeha.

Tradisi nampah batu merupakan simbol dimana masyarakat yang baru menikah akan sah menjadi warga desa Depeha setelah menjalani tradisi ini maka dari itu juga disebut dengan tradisi medesa anyar. Selain dua keunikan ini adapun yang melatar belakangi judul ini karena di latar belakangi oleh penelitaian terdahulu yang sejenis seperti : Penelitian dengan Judul Tradisi Ngedeblag di Desa Pakraman Kemenuh Kecamatan Sukawati Kabupaten Gianyar yang di teliti oleh Ni Putu Dian Yudiani, I Wayan Mandra dan Ketut Gunatra dengan hasil penelitian mengenai Prosesi Tradisi Ngedeblag di Desa Pakraman Kemenuh merupakan suatu kegiatan yang dilaksanakan setiap tahun yakni mulai pada sasih kalima secara turun temurun oleh krama desa, yang memiliki arti simbolis sebagai penghormatan kepada para bhuta kala agar senantiasa selalu memberikan keselamatan, kerahayuan, kesejahteraan, serta dapat menetralisir semua halhal yang bersifat negatif menajdi positif untuk keharmonisan lingkungan di Desa Pakraman Kemenuh, sehingga unsur bhuana alit dengan bhuana agung menjadi seimbang, serta dapat meningkatkan sraddha, dan bhakti umat Hindu kepada Ida Sang Hyang Widhi Wasa melalui media upakara (banten) untuk mendekatkan diri kepada-Nya sehingga dapat menumbuhkan keyakinan masyarakat akan adanya keagungan Tuhan Yang Maha Esa. Penelitian berikutnya adalah penelitaian yang dilakukan oleh: Darwan Sari, dengan judul penelitian Revitalisasi Tradisi Lisan Kantola Masyarakat Muna Sulawesi Tenggara Pada Era Globalisasi dengan hasil penelitian Deskripsi mengenai bentuk revitalisasi tradisi lisan kantola, dapat disimpulkan bahwa keberadaan tradisi lisan ini mulai tergantikan dengan produk budaya global.

Kondisi ini akan berakibat pada pemutusan pewarisan budaya, yang secara faktual, memang sedang berlangsung. Jika hal ini terus dibiarkan, maka salah satu produk budaya lokal yang tak ternilai harganya ini akan hilang. Penelitian yang ketiga adalah penelitian yang dilakukan oleh Irsyan Basri dengan judul penelitian Komodifikasi Ritual Duata Pada Etnik Bajo Di Kabupaten Wakatobi Provinsi Sulawesi Utara dengan hasil penelitian Ritual duata pada dasarnya dilaksanakan pada etnik Bajo yang memiliki garis ketururunan yang sama (Bajo). Ritual duata memiliki tujuan untuk meminta kesembuhan atau kekuatan dalam pengobatan dari berbagai penyakit yang secara medis tidak bisa disembuhkan. Untuk memohon permintaan keselamatan, diwujudkan dalam bentuk upacara keagamaan atau ritual. Ritual duata memiliki banyak nilai dan makna yang berkaitan dengan kehidupan masyarakat laut yang pada proses pelaksanaannya memerlukan waktu yang relatif lama.

Di lihat dari lokasi penelitian, disini peneliti menggunakan Desa Depeha Pada kajian tradisi nampah batu sebagai objek penelitian karena terdapat beberapa faktor yang memotivasi untuk dilakukannya penelitian di tempat tersebut mengenai pengintegrasian 
budaya nampah batu dalam pembelajaran IPS. Adapun faktor yang memengaruhi dilakukan pengintegrasian tradisi nampah batu di Desa Depeha untuk mengkaji nilai nilai karakternya adalah sebagai berikut: 1).Kurangnya tindakan inovasi dalam pembelajaran IPS dan minimnya pemahaman akan metode pembelajaran yang relevan, sehingga memberikan implementasi yang linear terhadap perkembangan dan kualitas peserta didik (siswa) karena kebanyakan guru-guru hanya mengajarkan siswa berpedoman pada buku panduan saja, disisi lain banyak materi lain yang ada disekitar siswa dapat dijadikan sebagai pembelajaran siswa misalnya tradisi maupun kebudayaan, 2). Banyak penelitian yang berusaha mengintegrasikan kebudayaan/tradisi dalam pembelajaran IPS akan tetapi pengkajian akan nilai-nilai karakter jarang dilakukan, karena sesuai dengan kurikulum yang berlaku saat ini setiap guru wajib menyisipkan pendidikan karakter dalam pembelajaran IPS maupun pembelajaran yang lain, 3). Pengetahuan dan wawasan tentang tradisi nampah batu didesa Depeha bagi kalangan masyarakat maupun siswa di SMP 5 Kubutambahan masih sangat minim, padahal jarak lokasi Desa Depeha dan SMP N 5 Kubutambahan sangat dekat, untuk itu perlu dilakukan pengintegrasian tradisi nampah batu dalam pembelajaran IPS di SMP N 5 Kubutambahan, 4). Adanya sebagian persepsi dan pandangan (ideologi) guru setempat, menganggap bahwa tradisi nampah batu bertentangan dengan pemahaman dan konsep jika diintegrasikan dalam pembelajaran IPS, 5). Materi pada buku teks yang digunakan oleh guru pada mata pelajaran IPS belum memberikan ruang dari segi substantif dan evaluative sehingga perlu dikembangkan dan melakukan inovasi pada pembelajaran IPS sehingga bisa meningkatkan kualitas dan pendidikan siswa terkait proses belajar mengajar setiap harinya.

Banyaknya tradisi kebudayaan dan kesenian yang dimiliki Bali memiliki makna dan fungsi tersendiri, sehingga kesenian dan tradisi yang dilaksanakan memiliki perbedaan dari pengeluaran biaya. Melihat serangkaian Tradisi dan kesenian Bali jika digunakan untuk hal keagamaan maka jumlah biaya yang dikeluarkan tidaklah sedikit. Pemeliharaan kebudayaan Bali sebagai sumber daya ekonomi hingga saat ini sepenuhnya menjadi tanggungan masyarakat desa. Biaya ini mencakup seluruh yang dikeluarkan oleh individu, keluarga, kelompok keluarga atau klan, kelompok sekeha, dan kelompok masyarakat yang terhimpun dalam satu desa. Sekalipun belum pernah diteliti secara khusus, pengeluaran untuk pemeliharaan budaya itu sangatlah besar. Masyarakat Bali tidak pernah mengkalkulasi dan mengeluhkan besaran biaya itu. Basis filosofi penyelenggaraan pengembanan budaya tersebut adalah keiklasan dan rasa bhakti kepada tuhan yang berurat dan berakar pada ajaran agama Hindu (Nurjaya, 2011: 1).

Tradisi-tradisi yang ada di Bali sebagian besar dapat di integrasikan dalam dunia Pendidikan. Mengingat pendidikan di Indonesia saat ini sangat mengironiskan maka diperlukan adanya pembangunan pendidikan disemua lini. Pembangunan Nasional di bidang pendidikan adalah upaya mencerdaskan kehidupan bangsa dan meningkatkan kualitas manusia Indonesia dalam mewujudkan masyarakat yang maju, adil, dan makmur berdasarkan Pancasila dan Undang-Undang Dasar 1945, yang memungkinkan warganya mengembangkan diri sebagai manusia Indonesia seutuhnya. Sistem pendidikan nasional diselenggarakan melalui dua jalur, yaitu jalur pendidikan sekolah, dan jalur pendidikan luar sekolah. Secara tradisional pendidikan dan berbagai tujuannya lebih menekankan pada ilmu pengetahuannya. Oleh karena itu, tanggung jawab sekolah hanya menyampaikan ilmu pengetahuan kepada para siswa dengan cara menghafal lantas mengkomunikasikan hafalan di hadapan guru. Hal itu dimaksudkan untuk mempersiapkan mereka agar berhasil dalam ujian terahir nanti. Selain itu, pendidikan memiliki tujuan dan tujuan pendidikan itu adalah untuk mendewasakan seluruh aspek yang dimiliki manusia, karena itu sudah tentu pendidikan harus menghadirkan suasana belajar yang secara langsung menyentuh pada pendidikan diberbagai aspek kehidupan. Tujuan pokok lain dari pendidikan adalah membentuk anggota masyarakat menjadi orang yang berpribadi, berperikemanusiaan maupun menjadi anggota masyarakat yang dapat mendidik dirinya sesuai dengan watak masyarakat itu sendiri, mengurangi beberapa kesulitan atau hambatan perkembangan hidupnya dan berusaha untuk memenuhi kebutuhan hidup maupun mangatasi problematika. Jadi jika dihubungkan dengan masyarakat maupun lingkungan, bahwa pendidikan 
merupakan kegiatan proses belajar mengajar yang sistem pendidikannya senantiasa berbeda atau berubah-ubah, dari satu masyarakat kepada masyarakat lain itu memiliki sistem sosial, filsafat dan gaya hidup tertentu yang sesuai dengan tujuan dasar maupun nilai-nilai yang terdapat di masyarakat (Ahmad, 2011:2).

Pemerintah memegang peranan penting dalam meningkatkan kualitas pendidikan anak-anak Indonesia, utamanya mulai dari ketersediaan sarana dan prasarana minimal berupa gedung sekolah yang layak, hingga sampai pada ketersediaan berbagai fasilitas pendukung pendidikan lainnya. Bagi sekolah-sekolah yang berada di perkotaan, sekolah yang rusak berat dan masih belum direhabilitasi sangat banyak ditemui, apalagi di daerahdaerah terpencil di Indonesia. Dengan kata lain, sekolah-sekolah diperkotaan saja kondisinya masih demikian, apalagi di pelosok Indonesia.

Pemerintah melalui Kemendiknas meluncurkan sebuah program pendidikan, yang dikenal dengan Pendidikan Karakter. Dominasi ranah kognitif dan psikomotorik harus dikurangi, ranah afektif sudah seharusnya menjadi fokus utama. Sehingga terbentuklah manusia-manusia yang berkarakter luhung, berbudi pekerti tinggi. Manusia-manusia seperti inilah yang diharapkan mampu membawa bangsa Indonesia menjadi jauh lebih baik, menjadikan Indonesia sebagai bangsa yang berbudaya tinggi. Pendidikan karakter dibutuhkan untuk mencegah setiap perbuatan-perbuatan yang tidak baik yang dapat merusak pendidikan di Indonesia. Oleh karena itu, semua peran sangat dibutuhkan untuk memajukan sistem pendidikan di Indonesia agar pendidikan di Indonesia mengalami pemerataan, peningkatan dan perubahan yang signifikan. Pendidikan Karakter bertujuan untuk memberikan pengetahuan tentang hal yang baik dan buruk, kemudian membuat hal yang baik menjadi suatu kebiasaan. Budaya ini harus dipelihara agar pendidikan di Indonesia berkembang dan bisa menjadi daya saing bagi pendidikan lainnya secara global. (Sumber: http://www.kompasiana.com)

Permasalahan pendidikan di Indonesia tidak akan pernah ada habisnya.Permasahan tersebut muncul pada setiap mata pelajaran di jenjang pendidikan Formal. IPS sebagai salah satu mata pelajaran di jenjang pendidikan dasar dan menengah tentunya memiliki permasalahan dalam pembelajran IPS pada umumnya muncul pada sisi tiori atau materi,proses pembelajaran ,sumber belajar dan media pembelajarannya. IPS sebagai mata pelajaran yang bertujuan untuk mengenal konsep-konsep yang berkaitan dengan kehidupan masyarakat dann lingkungannya,memiliki kemampuan dasar untuk berpikir logis dan kritis, rasa ingin tahu, inkuiri, memecahkan masalah, dan keterampilan dalam kehidupan sosial,memiliki komitmen dan kesadaran terhadap nilai-nilai sosial dan kemanusiaan, memiliki kemampuan berkomunikasi, bekerja sama dan berkompetisi dalam masyarakat yang majemuk, di tingkat lokal, nasional, dan global. Berdasarkan dari beberapa pandangan terkait tujuan pembelajaran IPS diatas, maka dapat ditarik kesimpulan bahwa dengan pembelajaran IPS diharapkan peserta didik peka terhadap masalahmasalah sosial yang terjadi di masyarakat dan menjadi warga negara yang baik dengan memiliki kemampuan dasar untuk berpikir logis dan kritis, rasa ingin tahu,inkuiri, memecahkan masalah, dan keterampilan dalam kehidupan sosial. Kemudian, Memiliki kesadaran dan kepedulian terhadap masyarakat ataulingkungannya, melalui pemahaman terhadap nilai-nilai sejarah dankebudayaan masyarakat. Dengan demikian sesungguhnya IPS memiliki banyak sumber belajar dan media pembelajaran. Sumber belajar dan media pembelajaran IPS sangat dekat dan pasti ada pada lingkungan sekitar siswa.

\section{Metode Penelitian}

Metode penelitian yang digunakan adalah metode penelitian kualitatif. Menurut Sukmadinata (2009:94), penelitian kualitatif ditujukan untuk memahami fenomena-fenomena sosial dari sudut atau perspektif partisipan. Partisipan adalah orang-orang yang diajak wawancara, diobservasi, diminta memberikan data, pendapat, pemikiran, dan persepsinya. Penelitian kualitatif mengkaji perspektif partisipan dengan multi strategi, strategi-strategi yang bersifat interaktif, seperti observasi langsung, observasi partisipatif, wawancara mendalam, dokumen-dokumen, teknik-teknik pelengkap seperti foto, rekaman, dan lain-lain. 
Metode ini digunakan untuk mendukung penelitian yang mengkaji Tradisi Nampoah Batu sebagai sumber pembelajaran IPS SMP untuk kelas VII. Data penelitian ini dianalisis secara kualitatif dan disajikan dalam bentuk naratif. Penelitian ini memaparkan makna, arti, dan fungsi dari data yang didapat oleh pelaku (informan).

\section{Hasil dan Pembahasan}

\section{a. Proses Tradisi Nampah Batu di Desa Depeha}

Belum ditemukan catatan atau sumber tertulis yang memberikan petunjuk kapan masyarakat Desa Depaha pertama kali menyelenggarakan upacara Nampah Batu.Tradisi Upcara Nampah Batu telah dilaksanakan secraa turun temurun oleh masyarakat Desa Depaha yang dirangkaikan dengan upacara pujawali di Pura Puseh.Pujawali di Pura Puseh Desa Depaha jatuh pada setiap Purnama sasih Karo.Walaupun upacara di Pura Puseh telah ditetapkan setiap Sasih Karo dalam kenyataan pelaksanaan upacara Nampah batu tidak mesti dilaksnakan setiap tahun. Pelaksanaan upacara Nampah Batu ditentukan oleh keputusan penghulu Desa berdasarkan perhitungan penanggalan Bali sehingga upacara nampah Batu bisa berlangsung setahu, dua tahun bahkan bisa lima tahun sekali. Pada hari purwani, sehari sebelum upacara pujawali di pura Puseh, oleh masyarakat Desa depaha disebut Nyumun sari, dilaksanakan upacara Nampah Batu atau Nampah Duwe. Upacara tersebut dirangkaikan dengan acara menek medesa, artinya warga masyarakat Desa Depaha yang gtelah melangsungkan upacara perkawinan yang dalam Agama Hindu disebut telah melaksanakan kehidupan Grhastha asmara wajib ikut melaksanakan upacara Nampah Batu Duwe. Walaupun belum ditemukan bukti tertulis tentang kapan pelaksanaan ritual Nampah Batu mulai dilakuan oleh warga Desa Depaha, tetapi tradisi lisan yang ada dalam masyarakat memberikan petujuk untuk mengetahui keberadaan upacara Nampah Batu sebagai salah satu tradisi unik yang masih dipertahankan sampai saat ini.

\section{b. Nilai -Nilai Karakter Dari Pelaksanaan Tradisi Nampah Batu yang Dapat dijadikan Sebagai Pengayaan Sumber Pembelajaran IPS Berbasis Kearifan Lokal di SMP N 5 Kubutambahan}

Nilai-nilai karakter pada tradisi ngangkid yang dapat diintegrasikan dalam pembelajaran IPS, berpedoman pada 18 nilai-nilai karakter yang direkomendasikan oleh Kemendiknas (2010). Keseluruhan 18 nilai karakter tersebut adalah religius, jujur, toleransi, disiplin, kerja keras, kreatif, mandiri, demokratis, rasa ingin tahu, semangat kebangsaan, cinta tanah air, menghargai prestasi, bersahabat/komunikatif, cinta damai, gemar membaca, peduli lingkungan, peduli sosial, dan tanggung jawab. Berpijak pada hasil temuan di lapangan, tidak secara keseluruhan dari komponen subak mencerminkan 18 nilai karakter tersebut, terdapat beberapa nilai karakter yang tidak tercermin dalam komponen tradisi nampah batu di Desa Depeha. Berdasarkan hasil wawancara dengan beberapa siswa di SMP N 5 Kubutambahan terdapat beberapa makna yang diungkapkan dari mengintegrasikan tradisi ngangkid dalam Pembelajaran IPS. Salah satu siswa tersebut adalah bernama I Komang Ariani ( 14 Tahun) yang berasal dari Banjar Dinas Pengubugan, Desa Depeha dia mengungkapkan bahwa setelah mengamati pelaksanaan tradisi nampah batu bahwa disana terdapat penggalan nilai karakter yang berupa nilai Gotong- royong, religius,kerjasama dan kepentingan bersama yang terdapat pada saat mengamati proses tradisi nampah batu di Desa Depeha. Sedangkan siswa lainnya yakni Made Pasek Gunawan (15 Tahun) yang berasal dari Banjar Dinas Seganti, Desa Depeha memiliki pendapat yang hampir sama, ia menyatakan bahwa ketika nilai karakter yang ditemukan dalam pengintegrasian tradisi ngangkid adalah sikap Religius, Kerja sama, gotong royong dan peduli sosial.

Pendapat lain diungkapkan oleh guru pengampu mata pelajaran IPS di kelas VII SMP

N 5 Kubutambahan Bapak Kadek Beni Astreawan S.Pd (33 Tahun), dalam hasil observasi dan wawancara, Beliau menyatakan bahwa nilai karakter banyak kita petik dalam pengintegrasian tradisi ngangkid ke dalam pembelajaran IPS misalkan sikap 
PIPS, Vol. 1 No. 1, Bulan April Tahun 2017

ISSN:2614-8366

disiplin, gotong-royong, kerja keras dan nilai pedui terhadap lingkungan,religius, kerjasama.

Kesimpulan bahwa tradisi nampah batu terdapat nilai spiritual yang mana tradisi ini bermakna untuk mendekatkan diri dengan tuhan yang dimulai dari menek medesa anyar. Berdasarkan hasil temuan tersebut, terdapat banyak jenis upacara ritual dalam pelaksanaan tradisi nampah batu. Upacara ritual tersebut tidak terlepas dari adanya karakter masyarakat yang religius dan percaya bahwa semua yang dilaksanakan dan yang diperoleh oleh krama desa merupakan berkah yang diberikan oleh Tuhan Yang Maha Esa. Oleh karena itu, krama desa telah mampu merepresentasikan karakter religius

\section{Simpulan}

Berdasarkan hasil dan pembahasan yang telah diuraikan, maka secara umum dapat disimpulkan bahwa:

1. Proses tradisi nampah batu bermula dari adanya paruman desa yang pelaksanaanya bertepatan pada purnama Karo yang biasanya bertepatan pada Bulan Agustus dan saat itu wajib tidak kena wuku wariga, apabila terkena wuku wariga maka tradisi nampah batu biasanya dilakukan tahun berikutnya sehingga tidak sembarang melakukan tradisi ini, Proses bermula dari adanya paruman kemudian membahas kesepakatan dan persiapan untuk melaksanakan piodal yang dilakukan dua kali pada saat tradisi berlangsung. Upacara dewa yadnya ( piodalan) yang dilaksankan di pura puseh, desa pakraman depeha, seperti biasa masyarakat dengan keyakinanya semua ngayah untuk mempersiapkan segala sarana dan prasarana upacara piodalan yang tempat pelaksanaannya dilakukan diareal jaba tengah pura puseh, desa pakraman Depeha.

2. Nilai-nilai karakter pada tradisi nampah batu yang dapat diintegrasikan dalam pembelajaran IPS, berpedoman pada 18 nilai-nilai karakter yang direkomendasikan oleh Kemendiknas (2010). Pembelajaran dengan menintegrasikan pendidikan karakter memang semakin diutamakan akhir-akhir ini, tradisi nampah batu mampu merepresentasikan sebagian nilai-nilai karakter yang berpedoman pada Kemendiknas (2010). Hasil penelitian menunjukkan terdapat 6 nilai karakter dari 18 nilai karakter Kemendiknas yang tercermin dan terepresentasikan pada tradisi nampah batu Dengan demikian, pemanfaatannya sebagai pemgembangan pembelajaran nilai-nilai karakter khususnya pada pembelajaran IPS sangat layak untuk diterapkan.

3. Pada dasarnya masih banyak sumber materi yang dapat dijadikan bahan dalam memberikan pengayaaan pada pembelajaran IPS, bukan hanya bertumpu pada sektor tradisi saja, melainkan juga aktivitas sosial berupa organisasi tradisional seperti subak maupun informal yang ada dilingkungan Desa Depeha yang dapat dijadikan sumber materi untuk pengayaan dalam pembelajaran IPS. Semuanya kembali lagi kepada pengemasan materi untuk pengayaan dalam pembelajaran IPS yang dapat dipadukan dengan berbagai metode inovatif lainnya.

4. Pada dasarnya masih banyak sumber materi yang dapat dijadikan bahan dalam memberikan pengayaaan pada pembelajaran IPS, bukan hanya bertumpu pada sektor tradisi saja, melainkan juga aktivitas sosial berupa organisasi tradisional seperti subak maupun informal yang ada dilingkungan Desa Depeha yang dapat dijadikan sumber materi untuk pengayaan dalam pembelajaran IPS.

\section{Daftar Rujukan}

Agung, Gede A.A. Tri Hita Karana Wujud Komunikasi Keluarga Semesta Dalam Perspektif Bali Kosmos. Universitas Pendidikan Ganesha.

Gunawan, Rudy. 2013. Pendidikan IPS (Filosofi, Konsep dan Aplikasi). Bandung: Alfabeta . 
PIPS, Vol. 1 No. 1, Bulan April Tahun 2017

ISSN:2614-8366

Gunawan, Iman. 2013. Metode Penelitiaan Kualitatif :Teori dan Pratilik. Jakarta: Bumi Aksara.

Nurhadi. 2003. Pembelajaran Konstektual ( Constektual Teaching and Learning/CTL). Malang: Universitas Negeri Malang.

Sukmadinata, Nana Syaodih. 2009. Metode Penelitian Pendidikan. Bandung : PT Remaja Rosdakarya.

Wardhana, Yana. 2010. Teori belajar dan mengajar. Bandung: Pribumi Mekar. 